\title{
Extracellular Vesicles in Hepatobiliary Malignancies
}

\author{
Ainhoa Lapitz ${ }^{1}$, Ander Arbelaiz ${ }^{1}$, Paula Olaizola ${ }^{1}$, Aitziber Aranburu ${ }^{1}$, Luis Bujanda ${ }^{1,2}$, \\ Maria J. Perugorria ${ }^{1,2,3 *}$ and Jesus M. Banales ${ }^{1,2,3 \star t}$
}

${ }^{1}$ Department of Liver and Gastrointestinal Diseases, Biodonostia Research Institute, Donostia University Hospital, University of the Basque Country (UPV/EHU), San Sebastian, Spain, ${ }^{2}$ "Centro de Investigación Biomédica en Red de Enfermedades Hepáticas y Digestivas" (CIBERehd), Carlos III National Institute of Health, Madrid, Spain, ${ }^{3}$ IKERBASQUE, Basque

Foundation for Science, Bilbao, Spain

\section{OPEN ACCESS}

Edited by:

Christoph Kahlert,

Universitätsklinikum Carl Gustav

Carus, Germany

Reviewed by:

Mallikarjun Bidarimath,

Cornell University, United States

Niels Halama,

Nationales Centrum für

Tumorerkrankungen (NCT), Germany

*Correspondence:

Maria J. Perugorria

matxus.perugorria@biodonostia.org

Jesus M. Banales

jesus.banales@biodonostia.org

tThese authors share senior authorship

Specialty section:

This article was submitted to Immunological Tolerance and Regulation,

a section of the journal

Frontiers in Immunology

Received: 18 February 2018

Accepted: 12 September 2018

Published: 12 October 2018

Citation:

Lapitz A, Arbelaiz A, Olaizola P,

Aranburu A, Bujanda L, Perugorria MJ and Banales JM (2018) Extracellular

Vesicles in Hepatobiliary Malignancies.

Front. Immunol. 9:2270.

doi: 10.3389/fimmu.2018.02270
Primary hepatobiliary malignancies include a heterogeneous group of cancers with dismal prognosis, among which hepatocellular carcinoma ( $\mathrm{HCC})$, cholangiocarcinoma (CCA), and hepatoblastoma $(\mathrm{HB})$ stand out. These tumors mainly arise from the malignant transformation of hepatocytes, cholangiocytes (bile duct epithelial cells) or hepatoblasts (embryonic liver progenitor cells), respectively. Early diagnosis, prognosis prediction and effective therapies are still a utopia for these diseases. Extracellular vesicles (EVs) are small membrane-enclosed spheres secreted by cells and present in biological fluids. They contain multiple types of biomolecules, such as proteins, RNA, DNA, metabolites and lipids, which make them a potential source of biomarkers as well as regulators of human pathobiology. In this review, the role of EVs in the pathogenesis of hepatobiliary cancers and their potential usefulness as disease biomarkers are highlighted. Moreover, the therapeutic value of EV regulation is discussed and future directions on basic and clinical research are indicated.

Keywords: extracellular vesicles, hepatocellular carcinoma, cholangiocarcinoma, hepatoblastoma, pathogenesis, therapy, diagnosis

\section{INTRODUCTION}

Liver cancer is a major health problem worldwide, representing the second leading cause of all cancer-related deaths (1). This cancer involves a heterogeneous set of hepatobiliary malignancies including hepatocellular carcinoma (HCC), cholangiocarcinoma (CCA), and hepatoblastoma (HB), which mainly arise from the malignant transformation of hepatocytes, cholangiocytes, and hepatoblasts, respectively $(1,2)$. Early non-invasive diagnosis, prediction of prognosis and treatment-response, as well as effective personalized therapies are still a challenge, highly compromising patient outcome (3-5).

HCC is the sixth most prevalent malignant tumor (10:100,000 incidence) and is strongly associated $(\sim 90 \%)$ with the presence of liver cirrhosis (LC) caused by alcohol, viral infections [hepatitis $\mathrm{B}(\mathrm{HBV})$ or $\mathrm{C}(\mathrm{HCV})$ viruses], and/or steatosis, among others $(5,6)$. CCA is a rare cancer, but its incidence $(\sim 5 / 100.000)$ is increasing worldwide. Although the etiology of the majority of CCAs is unknown, several risk factors may predispose for its development, including the presence of primary sclerosing cholangitis (PSC), liver fluke infections (endemic from East Asia), cirrhosis and congenital biliary disorders (3). On the other hand, $\mathrm{HB}$ is the most common pediatric liver malignancy, principally affecting children between 6 months and 3 years of age. HB is responsible 
for up to $\sim 1 \%$ of all pediatric cancers, with an annual incidence of $0.5-1.5$ cases $(4,7)$. Despite most $\mathrm{HB}$ cases are sporadic, some of them have been associated with hereditary cancer syndromes including familial adenomatous polyposis (FAP) and BeckwithWidemann syndrome (BWS), as well as with prematurity or low birth weight $(4,7)$. Since hepatobiliary malignances are usually diagnosed in late stages and are highly chemoresistant, the complete surgical resection of the tumors or liver transplantation constitute the only potential curative options. However, these therapeutic strategies are exclusively indicated under certain strict and conservative clinical criteria $(3,5,6)$. Therefore, there is an urgent need to determine new accurate non-invasive biomarkers for the early diagnosis of these diseases, as well as to monitor and predict disease progression and treatment response. Moreover, new effective personalized treatments are desirable in order to improve the outcome and life quality of patients.

During the last decade, extracellular vesicles (EVs) have opened new opportunities for non-invasive diagnosis and monitoring of human diseases. Their presence in biological fluids (serum, urine, bile, saliva, etc.) and their unique and diverse biomolecular composition (proteins, RNA, DNA, metabolites, and lipids) make EVs excellent candidates as a source of biomarkers $(8,9)$. Furthermore, since EVs participate in intercellular communication in human health and disease, they have been postulated as potential tools or targets for therapy. EVs are small membrane-encapsulated spheres produced and secreted by cells through complex and precise molecular

Abbreviations: 4F2hc, 4F2 cell-surface antigen heavy chain; A1AG1, alpha1-acid glycoprotein 1; A2MG, alpha-2-macroglobulin; ADAM10, disintegrin and metalloproteinase domain-containing protein 10; ADMSCs, adipose tissuederived mesenchymal stem cells; AFP, alpha-fetoprotein; AMPN, aminopeptidase N; ASGPR1, asialoglycoprotein receptor; APCs, antigen presenting cells; ASPGPR1, asialoglycoprotein receptor 1; AUC, area under the receiver operating curve; BWS, Beckwith-Widemann syndrome; CAF, cancer associated fibroblast; CBD, common bile duct; CCA, cholangiocarcinoma; CCL2/MCP-1, chemokine (C-C motif) ligand 2; CCNG1, cyclin G1; CDC, cell division protein; CDK, cyclin-dependent kinase; $\mathrm{CHB}$, chronic hepatitis $\mathrm{B}$; $\mathrm{CME}$, clathrin-mediated endocytosis; CXCL1, chemokine (C-X-C motif) ligand 1; DC, dendritic cell; DMA, dimethyl amiloride; EGFR, epidermal growth factor receptor; EIPA, 5ethyl-N-isopropyl amiloride; EPCAM, epithelial cell adhesion molecule; ESCRT, endosomal sorting complex required for transport; EVs, extracellular vesicles; FAP, familial adenomatous polyposis; FCN2, ficolin-2; FIBG, fibrinogen gamma chain; HB, hepatoblastoma; HBV, hepatitis B virus; $\mathrm{HCV}$, hepatitis $\mathrm{C}$ virus; HCC, hepatocellular carcinoma; HGF, hepatocyte growth factor; HSPs, heat shock proteins; HSPG, heparin sulfate proteoglicans; ICAM-1, intercellular adhesion molecule 1; IGF1R, insulin-like growth factor 1 receptor; IL, interleukin; ILVs, intraluminal vesicles; ITGB4, integrin $\beta 4$; ITIH4, inter-alpha-trypsin inhibitor heavy chain H4; LC, liver cirrhosis; LG3BP, galectin-3-binding protein; lincROR, long intergenic non-protein coding RNA regulator of reprogramming; lncRNA, long non-coding RNA; M $\beta C D$, methyl-b-cyclodextrin; MHC, major histocompatibility complex; MICB, MHC class I polypeptide-related sequence B; MMP, matrix metalloproteinase; MSC, mesemchymal stem cell; MVs, microvesicles; MVE, multivesicular endosome; NK cell, natural killer cell; NKT cell, natural killer $\mathrm{T}$ cell; nSMase, neutral sphyngomyelinase; PAFs, paracancer fibroblasts; PBX3, pre-B-cell leukemia transcription factor 3; PI3K, phosphoinositide-3-kinase; PIGR, polymeric immunoglobulin receptor; PLD2, phospholipase D2; PS, phosphatidylserine; PSC, primary sclerosing cholangitis; SNARE, soluble N-ethylmaleimide-sensitive factor attachment protein receptor; TAMPs, tumor-associated microparticles; VEGF, vascular endothelial growth factor; VNN1, pantetheinase; VTDB, vitamin-D binding protein. mechanisms (10-13). Traditionally, EVs are classified according to their biogenesis into exosomes, microvesicles (MVs) or microparticles, and apoptotic bodies $(11,12)$. Exosomes are referred to those EVs produced inside the multivesicular endosomes (MVEs) of the cells. Their morphology is spherical and the size ranges between 40 and $150 \mathrm{~nm}$ in diameter $(11,14,15)$. Cell MVEs are vesicular entities generated in the maturation process of the early endosomes, and where intraluminal vesicles (ILVs) are formed by the invagination of the MVE membrane. ILVs are the incipient exosomes that are released to the extracellular media upon the fusion of the MVEs with the plasma membrane of the cell (11). On the other hand, MVs or microparticles originate from the direct budding of the cell plasma membrane. Their size $(40-1000 \mathrm{~nm})$ and morphology are heterogeneous $(15,16)$. Apoptotic bodies are vesicles produced by cells undergoing apoptosis. Thus, their size ( $\sim 40$ to $2000-5000 \mathrm{~nm}$ ) and morphology are diverse (15, 16). Although this classification is widely accepted, to date, there are no specific biomarkers to differentiate exosomes from other types of nano-sized vesicle populations, limiting their specific isolation from biofluids. Therefore, the smallest vesicles (nano-vesicles) present and isolated from biological fluids comprise a mix of exosomes and plasma membrane-derived vesicles.

EVs have changed the paradigm of intercellular communication, which was traditionally restricted to the autocrine, paracrine and endocrine interaction through soluble proteins and lipids, or through direct cell-to-cell contact mediated by proteins, gap junctions, or tunneling nano-tubes in pluricellular organisms $(17,18)$. Accordingly, EVs contain an aqueous lumen and a specific subset of membrane and soluble proteins, nucleic acids (DNA and RNA), lipids and metabolites that can be horizontally transferred to local or distant cells by direct EV-cell membrane contact, fusion or internalization (12). The importance of EVs is highlighted by the fact that their composition is specific depending on the cell status and on the received stimuli $(19,20)$, which indicates a certain degree of selective packaging. EVs confer protection to the biomolecules enclosed inside the lipid bilayer, preventing their enzymatic degradation (21).

EVs participate in the regulation of multiple cancer hallmarks. They can transmit oncogenic signals by transferring pro-tumor RNAs and proteins that regulate diverse key processes in tumor progression such as proliferation, survival, differentiation, and invasion/migration of cancer cells (22-30). Additionally, EVs are involved in the crosstalk between tumor cells and stroma, promoting inflammation (31), cell matrix remodeling (32), neovascularization or angiogenesis $(33,34)$, chemoresistance (35-37), formation of the metastatic niche (38, 39), and inhibition of the anti-tumor immune response (40-42). Therefore, EVs represent key targets for therapy at various levels, including production, release and uptake by target cells. Additionally, the blockage or removal of tumor-derived EVs by apheresis with specific devices constitutes a potential therapeutic approach. Of note, EVs are also excellent candidates for the delivery of new anti-cancer proteins, RNAs, metabolites, drugs or cancer vaccines. 


\section{EV BIOGENESIS AND REGULATION}

$\mathrm{EV}$ production is a highly regulated and complex cellular process where several protein networks and diverse intracellular signals are involved (Figure 1). Among the different EV populations, the exosome production machinery is the best studied. Nevertheless, both exosomes and MVs share numerous mechanisms that participate in their biogenesis, release, and uptake (43). Regarding the mechanisms involved in the biogenesis of exosomes, the endosomal sorting complex required for transport (ESCRT) machinery has been reported to participate in MVE and ILV generation (44). However, ESCRT independent mechanisms have also been described in the formation of exosomes, including ceramide production by neutral type II sphingomyelinase (nSMase2) $(45,46)$, lipid rafts (47), phospholipase D2 (PLD2) $(48,49)$, and tetraspanin family of proteins (e.g., CD9, CD63, and CD81) $(50,51)$, which form dynamic membrane microdomains that promote their budding and assure exosome formation.

Intracellular trafficking of MVEs is coordinated by the cytoskeleton and motor proteins such as dynein (52) and Rab family of GTPases (Figure 1) (53). MVEs fuse with the plasma membrane via SNARE proteins, finally allowing exosome secretion $(53,54)$. In contrast, MVs arise as a result of the direct budding of the cell plasma membrane. Their biogenesis requires $\mathrm{Ca}^{2+}$-dependent membrane phospholipid and cytoskeleton rearrangements, which enable MV blebbing and release (55). Released EVs are recognized by the recipient cells through specific interactions between their membrane components. These include integrins, lipids, tetraspanins, proteoglycans, among others (56). Plasma membrane-bound EVs can be internalized through clathrin-mediated endocytosis (CME) or clathrin-independent processes that include phagocytosis, macropinocytosis and lipid rafts.

Several experimental strategies have targeted the aforementioned mechanisms to interfere with EV production, release and uptake at different levels (Figure 1). Among these, intervention on ceramide production has been the most widely used strategy to decrease exosome production in cancer cells and thereby abolish the multiple oncogenic effects of tumorderived exosomes in several cancers. Experimental inhibition of nSMase2, responsible for ceramide production, with its inhibitor GW4869 reduces exosome secretion $(45,57)$ and sensitizes cancer cells to chemotherapy (58). Of note, the presence of GW4869 inhibits the migratory capacity of CCA cells (31). Several intercellular signals involved in the regulation of the EV production are also under investigation, including the reduction of intracellular $\mathrm{Ca}^{2+}$ concentration. In fact, the $\mathrm{Na}^{+} / \mathrm{Ca}^{+2}$ exchange inhibitor dimethyl amiloride (DMA) leads to diminished $\mathrm{EV}$ production in lymphoma cells, resulting in an enhanced anti-tumor immune response (40). Regarding the proteins that participate in the transport of exosomes, Rab family proteins are key mediators of MVE transit to the plasma membrane, their inhibition being linked to a decrease of exosome release (59). Accordingly, the repression of Rab27a diminished growth and dissemination of cancer cells in vivo $(39,60)$.
Different complex mechanisms, including protein and/or lipid interactions between EV and recipient cell surface components, are required for the EV cell uptake (Figure 1). These mechanisms include phagocytosis, macropinocytosis, clathrin, and caveolin dependent endocytic pathways, as well as lipid raft-mediated and membrane fusion processes (56). Therefore, aiming to block tumor EV uptake processes, different components of these machineries have been targeted. Membrane proteins including tetraspanins, integrins, lectins, proteoglycans, major histocompatibility complex (MHC) molecules, glycoproteins and other receptors are involved in EV-recipient cell interaction. Tetraspanins, enriched proteins present in EVs and wellestablished markers of these vesicles $(61,62)$, participate in EVcell surface adhesion mediating their uptake. Thus, antibodybased inhibition of the CD81 and CD9 tetraspanins as well as the blockade of $\alpha \mathrm{V}$ and $\beta 3$ integrins, hampers EV uptake $(63,64)$. Lectins, such as galectin-5, can also be targeted with the glycoprotein asialofetuin to interfere with EV-cell interaction and the subsequent cellular internalization (65). Likewise, targeting the lectin receptors DC-SIGN or DEC-205 with specific antibodies also results in a reduction of EV uptake $(66,67)$. Heparin can also block the internalization of cancer EVs by binding to the cell surface heparan sulfate proteoglycans $(68,69)$. Furthermore, the pivotal interaction between EVs and the plasma membrane of the cell can be partially inhibited by proteinase $\mathrm{K}$ treatment, blocking $\mathrm{EV}$ recognition and the subsequent endocytic process in cancer cells (70).

The best studied EV internalization mechanisms are related with the endocytic pathway $(63,70,71)$. Since these processes depend on the cytoskeleton, the inhibition of actin polymerization by cytochalasin D reduces EV uptake by phagocytosis $(56,70,71)$. In addition, the uptake of EVs by macrophages can be abrogated by the inhibition of phosphoinositide-3-kinase (PI3K) with wortmannin or LY294002 (72). Moreover, inhibitors of macropinocytosis or CME [5-ethyl-N-isopropyl amiloride (EIPA) and chlorpromazine, respectively] reduce tumor-derived EV internalization (70). Dynasore can also impair CME through the inhibition of dynamin 2, needed for clathrin-coated endosome membrane fission $(65,73-76)$. On the other hand, certain endocytic processes are closely related to lipid rafts, and the intervention on their composition impairs the uptake of EVs. Thus, the use of the glycosphingolipid synthesis inhibitors [i.e., fumosinin $\mathrm{B} 1$ and $\mathrm{N}$-butyldeoxynojirimycin hydrochloride (also known as CAS72599)] reduces EV uptake (77). Cholesterol reducing agents including methyl-beta-cyclodextrin $(\mathrm{M} \beta \mathrm{CD})$ $(70,78,79)$, filipin $(71,79)$ and simvastatin, as well as the inhibition of ERK1/2 signaling by U0126 may also impair the uptake of EVs (79). Masking phosphatidylserine (PS), present in the membrane surface of EVs, by Diannexin and blocking its receptor TIM4 inhibits epidermal growth factor receptor (EGFR) transfer from tumor EVs to endothelial cells resulting in reduced tumor growth and microvascular density in vivo (80). EVs can also release their content into the recipient cells by the direct fusion of plasma and EV membranes. This fusion is enhanced in acidic conditions, a general feature of cancer cells (81). In this 


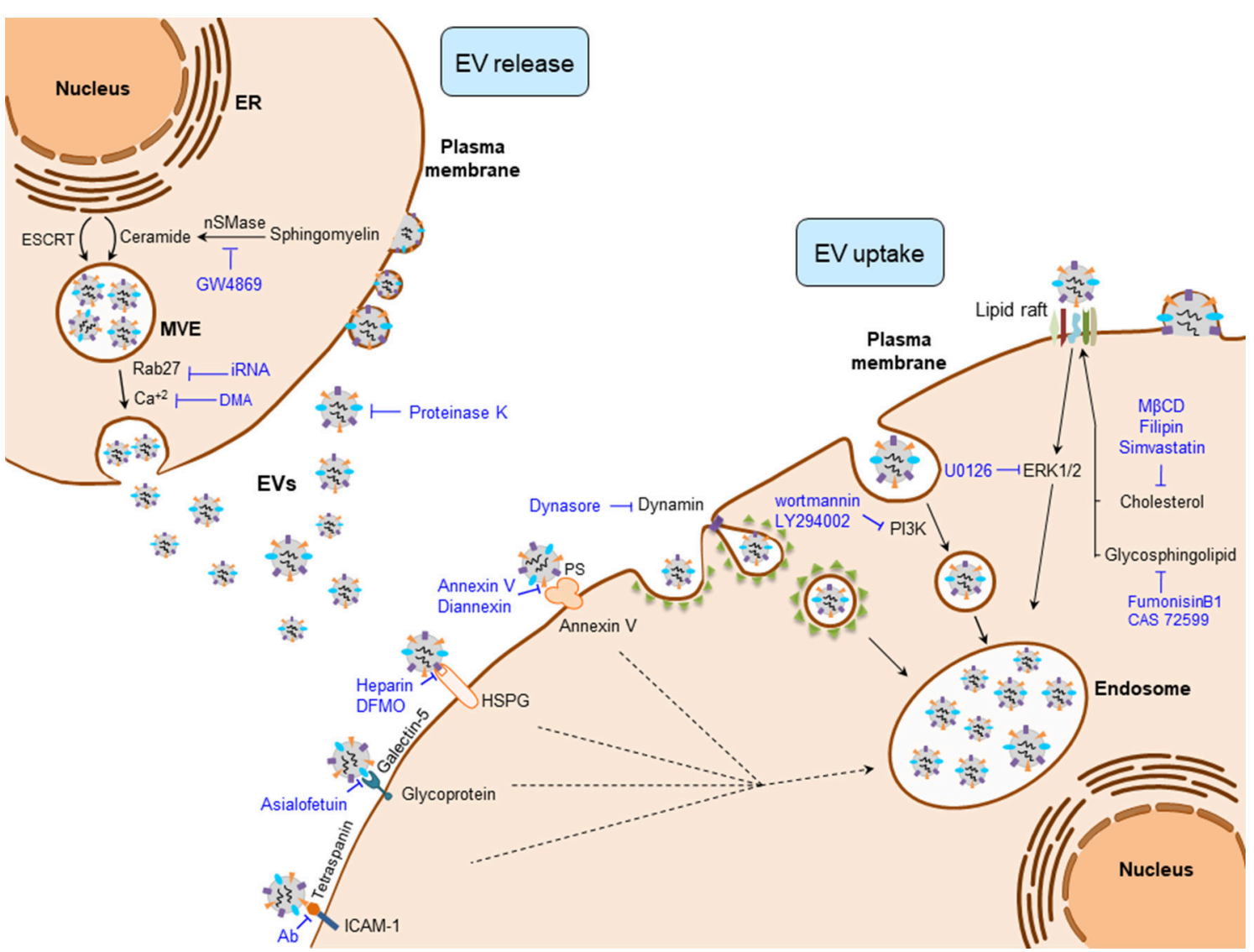

FIGURE 1 | Regulatory mechanisms of EV biogenesis, release, and uptake. Exosome release can be inhibited by interfering their biogenesis (e.g., ceramide production) or the membrane fusion of the multivesicular endosome (MVE) with the plasma membrane (e.g., Rab27). Once EVs are released to the extracellular milieu, their uptake can be blocked by interfering the EV-plasma membrane protein interactions (e.g., Tetraspanins), clathrin- and caveolin-dependent endocytosos (e.g., Dynasore), phagocytosis (e.g., Wortmannin), and by inhibiting lipid-raft mediated endocytosis (e.g., Filipin). DFMO, difluoromethylornithine; DMA, dimethyl amiloride; ESCRT, endosomal sorting complex required for transport; EVs, extracellular vesicles; HSPG, heparan sulfate proteoglycans; ICAM-1, intercellular adhesion molecule 1; M $\beta C D$, methyl- $\beta$-cyclodextrin; nSMase, neutral sphingomyelinase; PS, phosphatidylserine.

sense, proton pump inhibition leads to reduced EV uptake by cancer cells (82).

\section{EVs IN HEPATOBILIARY CANCERS}

\section{Hepatocellular Carcinoma}

HCC cell-derived EVs participate in autocrine and/or paracrine cellular communications, regulating tumor growth, chemoresistance, angiogenesis, and dissemination. Several lines of evidence indicate that HCC cell-derived EVs promote tumor resistance against chemotherapeutic drugs such as sorafenib, doxorubicin or camptothecin. For instance, an enrichment of long intergenic non-coding RNA regulator of reprogramming (linc-ROR) in EVs derived from sorafenib-treated HCC cells prevents chemotherapy-induced apoptosis through p53 repression and increases the expression of tumor-initiating liver cancer stem cell CD133 marker (83). Another molecular mechanism involved in HCC cell-derived EV-induced sorafenib resistance includes the activation of the hepatocyte growth factor (HGF)/c-Met/Akt signaling pathway in liver cancer cells (84).

EVs derived from HCC cells may also regulate angiogenesis (85). Experimental in vitro models indicate that EVs derived from CD90+ liver cancer cells (i.e., cancer stem-like cells present in primary tumors and blood of HCC patients, associated with metastasis as well as bad prognosis) are enriched in long noncoding RNA (lncRNA) H19, which promotes the expression of vascular endothelial growth factor (VEGF) and its receptor VEGF-R1 in endothelial cells. Moreover, lncRNA H19 stimulates tube formation as well as cell-adhesion properties in endothelial cells, inducing the expression of intercellular adhesion molecule 1 (ICAM-1) in this cell-type.

Concerning the role of EVs in metastasis, several studies have reported that EVs secreted from HCC cells or from adjacent cells are also involved in the promotion of tumor cell metastasis (86). Transcriptomic and proteomic profiling revealed that EVs derived from metastatic HCC cells carry a larger number of protumorigenic RNAs and proteins, such as MET proto-oncogene, 
S100 family members (S100A4, S100A10, and S100A11) and the caveolins (CAV1 and CAV2). HCC-derived EVs trigger the activation of PI3K/Akt and MAPK signaling pathways and the secretion of active MMP2 and MMP9 matrix metalloproteinases (MMPs) in hepatocytes, which in turn enhance their migratory and invasive ability. On the other hand, cancer-associated fibroblast (CAF)-derived EVs may also contribute to HCC cell proliferation and metastasis (87). Thus, a reduction in the miR320a level was observed in CAF-derived EVs compared to paracancer fibroblasts (PAFs). This miR-320a directly targets pre-Bcell leukemia transcription factor 3 (PBX3), suppressing HCC cell proliferation, migration, and invasion. The anti-tumor effects of miR-320a were confirmed in vivo using HCC tumor xenograft models, in which tumor growth was inhibited when HCC cells were co-injected with miR-320a over-expressing CAFs into nude mice. Besides EVs derived from CAFs, innate immune cellderived MVs have also been reported to enhance HCC metastasis through CD11b and CD18, also known as integrin $\alpha_{M} \beta_{2}$ (88).

\section{Cholangiocarcinoma}

The presence of EVs in bile and their role regulating cholangiocyte physiology was first described in murine models (89). However, EVs also play a role in biliary pathobiology. In CCA tumors, several reports have emphasized the importance of EVs in the regulation of the interplay between CCA cells and the cells present in the tumor stroma. CCA cell-derived EVs favor the fibroblastic differentiation of bone marrowderived mesenchymal stem cells (MSCs) and the secretion of pro-inflammatory cytokines and chemokines, including interleukin (IL)-6, chemokine (C-X-C motif) ligand 1 (CLXC1), and chemokine (C-C motif) ligand 2 (CCL2/MCP-1), which ultimately stimulate CCA cell proliferation via IL6/STAT3 signaling pathway (31).

CCA-derived EVs may contain oncogenic biomolecules not only involved in modulating inflammatory and proliferative responses but also controlling migratory and metastatic processes. Two studies employing comparative proteomic approaches have explored the protein content of CCAderived and cholangiocyte-derived EVs in vitro, identifying significant differences and a particular oncogenic protein profile related to proliferation and motility in cancer cell-derived EVs (90, 91). Differentially expressed proteins involved in cholangiocarcinogenesis included EGFR, Mucin-1, integrin $\beta 4$ (ITGB4), and epithelial cell adhesion molecule (EPCAM) (90). EGFR participates in CCA progression, favoring the dedifferentiation and invasiveness of tumor cells and represents a bad prognostic factor $(92,93)$. Similarly, Mucin-1 and EPCAM, which are also upregulated in CCA, correlate with poor outcome in patients with CCA (94-96). Interestingly, ITGB4 has recently been described as an EV integrin that dictates future metastatic sites, contributing to preferential organotropism of tumor cells (38). On the other hand, EVs secreted by liver-fluke associated CCA cells induce cholangiocyte proliferation (97) and invasion (91), events that are associated with an enrichment of oncoproteins in EVs, including galectin-3 binding protein (LG3BP), prostaglandin $\mathrm{F} 2$ receptor negative regulator, 4F2 cell-surface antigen heavy chain (4F2hc), integrin- $\beta 1$ and EPCAM (91).

\section{NON-INVASIVE BIOMARKERS}

The presence of EVs in biological fluids and their diverse molecular cargo has recently placed EVs as a new source of non-invasive disease biomarkers. Indeed, potential biomarker candidates (miRNAs and proteins) have been described in serumand bile-derived EVs for the diagnosis and/or the prognosis prediction of HB, HCC, and CCA (Table 1).

In $\mathrm{HB}$ patients, serum EV miR-21 levels were higher than in healthy children, and negatively correlated with patient survival (98). On the other hand, decreased levels of miR-34a, miR$34 \mathrm{~b}$, and miR-34c were reported in serum EVs from HB infants compared to healthy individuals. Combination of these miRs showed higher diagnostic value than the gold standard alpha fetoprotein (AFP) (99). Furthermore, reduced levels of the miR34 panel in EVs of HB were associated with lower overall survival (99).

In HCC patients, levels of miRs 18a, 221, 222, and 224 in serum EVs were found upregulated compared to patients with chronic hepatitis $\mathrm{B}(\mathrm{CHB})$ or liver cirrhosis, patients, whereas miR-101 level was downregulated (105). Likewise, increased expression of miR-21 was identified in serum EVs from patients with HCC compared to $\mathrm{CHB}$ patients or healthy individuals, and correlated with cirrhosis and advanced tumor stage (106). MiR665 in serum EVs may also be a potential prognostic biomarker for HCC, as high miR-665 levels positively correlated with larger tumor size, local invasion and advanced clinical stages (stage III/IV), and negatively with overall survival (107). Moreover, diminished levels of several miRNAs in serum EVs have been suggested as predictors of HCC recurrence or overall survival $(108,109)$. MiR expression profiling in serum EVs identified the tumor suppressor miR-718 downregulated in patients with larger tumor diameters and recurrence. Reduced miR-718 expression also correlated with poor histological tumor cell differentiation (108). Furthermore, low levels of miR-125b in serum EVs have been linked to advanced TNM stages and encapsulation, suggesting this $\mathrm{miR}$ as a potential prognostic candidate of recurrence and overall survival (109). Besides miRNAs, different proteins present in serum EVs such as LG3BP, polymeric immunoglobulin receptor (PIGR) and alpha-2-macroglobulin (A2MG) were found upregulated in HCC patients compared to healthy individuals, with a better diagnostic value than AFP (90). Apart from changes in the EV cargo, the EV concentration itself could also serve as a disease biomarker. In fact, stage I and II HCC patients showed higher EV concentration in serum compared to patients with liver cirrhosis (100).

In CCA, a panel of miRs (191, 486-3p, 1274b, 16, 484) was found upregulated in bile EVs of patients with CCA compared to a control group containing PSC, biliary obstruction and bile leak syndrome patients (102). The analysis of the lncRNA profile in bile EVs from CCA patients vs. patients with biliary obstruction identified the upregulation of two lncRNAs (i.e., ENST00000588480.1 and ENST00000517758) in 
TABLE 1 | EVs as non-invasive biomarkers of hepatobiliary malignancies.

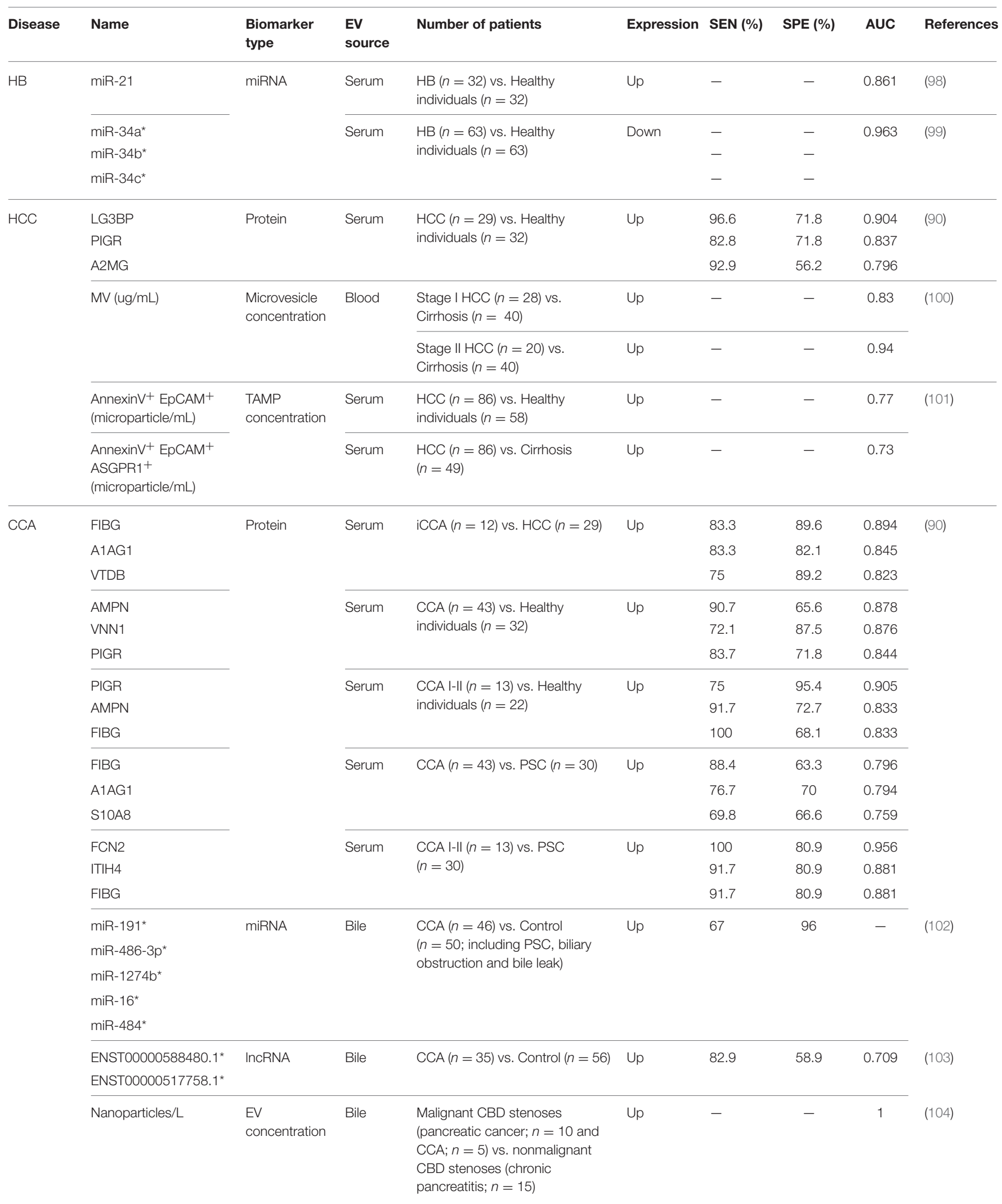


TABLE 1 | Continued

\begin{tabular}{|c|c|c|c|c|c|c|c|c|c|}
\hline Disease & Name & $\begin{array}{l}\text { Biomarker } \\
\text { type }\end{array}$ & $\begin{array}{l}\text { EV } \\
\text { source }\end{array}$ & Number of patients & Expression & SEN (\%) & SPE (\%) & AUC & References \\
\hline & $\begin{array}{l}\text { AnnexinV }^{+} \text {EpCAM }^{+} \\
\text {ASGPR1 }^{+} \\
\text {(microparticle/mL) }\end{array}$ & $\begin{array}{l}\text { TAMP } \\
\text { concentration }\end{array}$ & Serum & $\begin{array}{l}\text { CCA }(n=38) \text { vs. Cirrhosis } \\
(n=49)\end{array}$ & Up & - & - & 0.63 & (101) \\
\hline $\begin{array}{l}\text { Liver } \\
\text { cancer } \\
\text { (HCC/CCA) }\end{array}$ & $\begin{array}{l}\text { AnnexinV }^{+} \mathrm{EpCAM}^{+} \\
\text {ASGPR1 }^{+} \\
\text {(microparticle/mL) }\end{array}$ & $\begin{array}{l}\text { TAMP } \\
\text { concentration }\end{array}$ & Serum & $\begin{array}{l}\text { Liver tumor (HCC; } n=86 \text { and } \\
\text { CCA; } n=38 \text { ) vs. Cirrhosis } \\
(n=49)\end{array}$ & Up & - & - & 0.7 & (101) \\
\hline
\end{tabular}

A1AG1, alpha-1-acid glycoprotein 1; A2MG, alpha-2-macroglobulin; AMPN, aminopeptidase N; ASPGPR1, asialoglycoprotein receptor 1; AUC, area under the receiver operating curve; CBD, common bile duct; CCA, cholangiocarcinoma; EpCAM, epithelial cell adhesion molecule; FCN2, ficolin-2; FIBG, fibrinogen gamma chain; iCCA, intrahepatic cholangiocarcinoma;

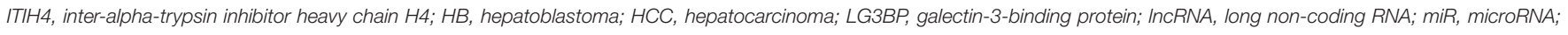

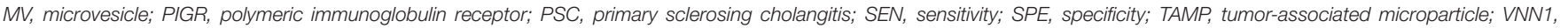
pantetheinase; VTDB, vitamin-D binding protein. *biomarker panel.

CCA patients (103). The combined expression of both lncRNAs showed relevant diagnostic and prognostic value, being increased in advanced TNM stages (III-IV) and showing worse overall survival at high lncRNA concentrations. On the other hand, different proteins present in serum EVs exhibited high diagnostic values when comparing CCA patients with healthy individuals, such as aminopeptidase $\mathrm{N}$ (AMPN), pantetheinase (VNN1), and PIGR (90). Some proteins present in serum EVs, such as ficolin-2 (FCN2), inter-alpha-trypsin inhibitor heavy chain $\mathrm{H} 4$ (ITIH4) and fibrinogen gamma chain (FIBG), displayed better diagnostic values than CA19-9 (a non-specific tumor marker for the diagnosis of CCA) in the differential diagnosis between CCA (stage I-II) and PSC (90). Nowadays, the differential diagnosis between intrahepatic CCA (iCCA) and HCC by non-invasive methods is not feasible and compromises adequate treatment. In this regard, proteins present in serum EVs-such as FIBG, alpha-1-acid glycoprotein 1 (A1AG1) and vitamin-D binding protein (VTDB) - exhibited higher accuracy than CA19-9 and AFP for the differential diagnosis of iCCA vs. HCC (90). As aforementioned, the EV concentration analysis could also be relevant for the diagnosis of malignant biliary diseases. In this regard, bile EV concentration was reported to accurately discriminate between malignant common bile duct (CBD) stenosis and nonmalignant CBD stenosis (104). In addition, elevated concentration of AnnexinV/EpCAM/ASGPR1 positive tumor-associated microparticles (TAMPs) allowed the diagnosis of patients with liver cancer (HCC and CCA) compared to cirrhotic patients, while no changes were detected between HCC and CCA (101). Notably, the levels of these TAMPs decreased 7 days after the surgical resection of liver tumors, closely relating this microparticle population with tumor presence.

\section{THERAPEUTIC IMPLICATIONS}

The use of EVs in anti-cancer therapy is currently under investigation. As EVs carry different types of molecules, they can be used as vehicles to deliver therapeutic cargo into cancer cells (110). Moreover, EVs have shown the ability to modulate the immune system, and to stimulate the immune response against tumor cells (111).

\section{Molecule Carriers}

EVs as therapeutic delivery systems provide benefits for the carried therapeutic molecule. Hence, encapsulation of therapeutic compounds (such as chemicals, RNAs, DNAs, proteins, or lipids) increases their bioavailability by preserving their integrity and biological activity, as well as protecting them from enzymatic degradation in biological fluids (112). In comparison to other therapeutic vectors such as synthetic nano-particles, liposomes or recombinant viral vectors, EVs are generally non-immunogenic in nature, which enhances their resistance to fast clearance from circulation (112). EVs also display low toxicity and are quite stable in tissues and circulation, representing adequate therapeutic delivery systems against cancer (113). Furthermore, cell type-specific proteins within EVs seem to provide certain cell tropism (112).

The strategy of using EVs as therapeutic molecule delivery vehicles is starting in liver cancer, mainly focusing on miRNAs. Stellate cell-derived EVs loaded with miR-335-5p, a tumor suppressor miR downregulated in HCC, inhibits HCC cell invasiveness in vitro and induces HCC tumor shrinkage in vivo through the repression of proliferation and stimulation of apoptosis (114). Moreover, miR-122 enriched EVs obtained from adipose tissue-derived mesenchymal stem cells (ADMSCs) increases HCC cell sensitivity to the chemotherapeutic agents sorafenib and 5-FU (115). The underlying mechanism regulating chemosensitivity consists on the downregulation of miR-122 target genes including cyclin G1 (CCNG1), disintegrin and metalloproteinase domain-containing protein 10 (ADAM10), and insulin-like growth factor 1 receptor (IGF1R), which induce apoptosis and cell cycle arrest in vitro. Furthermore, intratumor injection of miR-122-enriched EVs in a HCC xenograft mouse model synergized the inhibitory effect of sorafenib in vivo, reducing tumor size (115).

In CCA, stellate cell-derived EVs carrying miR-195 inhibited CCA growth and invasiveness in vitro (116). Tail vein injection of miR-195 loaded EVs into an orthotopic rat model of CCA reduced tumor size and improved the overall animal survival (116). These anti-neoplasic effects are likely mediated via targeting VEGF, cell division control (CDC) proteins 25 and 42, as well as cyclin-dependent kinases (CDK) 1, 4, and 6. 


\section{Immunotherapy}

An alternative therapeutic strategy contemplates the use of EVs as stimulators of the immune system in order to elicit a nontoxic, systemic, and long-lived anti-tumor immune response. Different studies have described the potential use of EVs as immunostimulatory entities against HCC (117121). For instance, HCC cells under stress conditions, such as heat shock or chemotherapeutic anti-cancer drug treatment, increased EV secretion and surface expression of heat shock proteins (HSPs) (117). HSP-bearing EVs can boost natural killer (NK) cell-mediated cytotoxic response against HCC cells in vitro (117). Similarly, histone deacetylase inhibitor MS-275 enhanced the protein levels of immunostimulatory molecules [MHC class I polypeptide-related sequence B (MICB) and HSP70] in EVs derived from HCC cells, increasing the cytotoxicity of NK cells and anti-tumor response (118). The anti-HCC tumor immune response can also be induced by ADMSC-derived EVs, which promote natural killer $\mathrm{T}$ cell (NKT) anti-tumor response, thereby facilitating HCC suppression (119).

Alternatively, HCC cell-derived EVs display HCC antigens AFP and glypican 3. Capture of these EVs by dendritic cells (DCs) triggers a strong DC-mediated T cell dependent antitumor immune response both in vitro and in ectopic and orthotopic in vivo mouse models (120). EVs from antigen presenting cells (APCs) can also induce anti-tumor immune responses against HCC. EVs derived from AFP-expressing DCs are able to trigger potent antigen-specific anti-tumor immune responses and reshape the tumor microenvironment from an immunoinhibitory to an immunostimulatory setting in diverse HCC mice models including ectopic, orthotopic and carcinogeninduced HCC (121). Thus, AFP-expressing DC-derived EVs stimulate antigen-specific anti-tumor immune responses in vivo, eliciting suppression of tumor growth and prolonging mice survival (121).

\section{CONCLUDING REMARKS AND FUTURE DIRECTIONS}

Early diagnosis and treatment of hepatobiliary malignancies is still far from being manageable. The development of noninvasive diagnostic and disease monitoring tools represents a major challenge. The presence of EVs in biological fluids, as well as their capacity to carry tumor-associated molecules, make EVs excellent candidates for clinical application. Hereof, certain progress is being made in the potential use of EVs as a source of non-invasive disease biomarkers. EV concentration as well as their specific cargo can serve as indicators of the different pathological stages of a disease, including the discrimination between early and late phases, and estimation of recurrence and metastasis risk. For that matter, the application of omic technologies has provided some potential candidate biomarkers. However, in order to transfer knowledge into the clinical practice, several limitations, and concerns should be considered: (i) different EV isolation procedures (i.e., ultracentrifugation, size exclusion, immune-affinity isolation, polymeric precipitation, and microfluidics) are currently used, providing diverse EV populations and yield depending on the nature of the isolation protocol (ii) a proper characterization of the EVs fraction should be performed. There are minimal experimental requirements defined by the International Society for Extracellular Vesicles (ISEV) (122), which include the analysis of the EV quantity [e.g., nanoparticle tracking analysis (NTA), IZON qNano technique, flow cytometry], size [e.g., NTA, IZON qNano technique, electron microscopy, dynamic light scattering (DLS)], and presence of specific surface markers (e.g., immunoblot, immune-gold electron microscopy) (122, 123), (iii) specific EV markers to distinguish EV subpopulations according to their origin (e.g., exosomes, MVs, apoptotic bodies) are still missing (122), (iv) appropriate clinicallyrelevant control groups with biopsy-proven diagnosis, as well as a representative number of samples should be included to ensure the accuracy (sensitivity, specificity, AUC, predictive and likelihood ratio values) and significance of the results (124), (v) candidate biomarkers identified in a discovery phase must be internationally validated using easily transferable methodologies into the clinical settings (e.g., ELISA, qPCR), ideally using raw biological fluids (i.e., serum, urine, saliva) and avoiding the costly and time consuming EV isolation techniques.

EVs represent a new opportunity for cancer therapy. They participate in the development and progression of cancer, including the formation of a pro-tumorigenic microenvironment, angiogenesis, chemoresistance, and the generation of a metastatic niche, promoting tumor growth, and aggressiveness. Therefore, interfering the EV biogenesis and/or release may be a potential therapeutic strategy. Several inhibitors targeting these crucial steps have been developed (Figure 1), although their safety and efficacy should be clinically evaluated in the future. Nevertheless, additional regulatory mechanisms of EV generation (e.g., loading), trafficking and autocrine/paracrine signal transduction (e.g., recipient cell internalization routes of specific EV subpopulations) need to be elucidated, which could provide other targets for therapy (125). On the other hand, EVs could be used as drug delivery systems and as immunomodulators promoting anti-tumor response. For drug delivery, a major challenge represents the specific cell targeting in vivo, as well as the use of immunologically inert and biocompatible EVs. In contrast, the capacity of EVs to regulate the immune system opens new opportunities for targeting malignancies and for developing anti-tumor vaccines (126).

In conclusion, EVs represent an emerging and stimulating field of research in liver cancer with multiple potential applications, from biomarker discovery to therapy. Nonetheless, thorough research is still needed to gain knowledge on their intrinsic role in liver health and disease, and to evaluate their potential clinical application.

\section{AUTHOR CONTRIBUTIONS}

All authors listed have made a substantial, direct and intellectual contribution to the work, and approved it for publication. 


\section{FUNDING}

Spanish Ministries of Economy and Competitiveness [JB (FIS PI12/00380, FIS PI15/01132 and Miguel Servet Programme CON14/00129); MP (FIS PI14/00399, FIS PI17/00022) and Ramon y Cajal Programme RYC-2015-17755] cofinanced by Fondo Europeo de Desarrollo Regional (FEDER); ISCIII

\section{REFERENCES}

1. Sia D, Villanueva A, Friedman SL, Llovet JM. Liver cancer cell of origin, molecular class, and effects on patient prognosis. Gastroenterology (2017) 152:745-61. doi: 10.1053/j.gastro.2016.11.048

2. Rizvi S, Gores GJ. Pathogenesis, diagnosis, and management of cholangiocarcinoma. Gastroenterology (2013) 145:1215-29. doi: 10.1053/j.gastro.2013.10.013

3. Banales JM, Cardinale V, Carpino G, Marzioni M, Andersen JB, Invernizzi P, et al. Expert consensus document: Cholangiocarcinoma: current knowledge and future perspectives consensus statement from the European Network for the Study of Cholangiocarcinoma (ENS-CCA). Nat Rev Gastroenterol Hepatol. (2016) 13:261-80. doi: 10.1038/nrgastro.2016.51

4. Czauderna P, Lopez-Terrada D, Hiyama E, Haberle B, Malogolowkin MH, Meyers RL. Hepatoblastoma state of the art: pathology, genetics, risk stratification, and chemotherapy. Curr Opin Pediatr. (2014) 26:19-28. doi: 10.1097/MOP.0000000000000046

5. Forner A, Reig M, Bruix J. Hepatocellular carcinoma. Lancet (2018) 391:1301-14. doi: 10.1016/S0140-6736(18)30010-2

6. Bruix J, Gores GJ, Mazzaferro V. Hepatocellular carcinoma: clinical frontiers and perspectives. Gut (2014) 63:844-55. doi: 10.1136/gutjnl-2013-306627

7. Schnater JM, Kohler SE, Lamers WH, von Schweinitz D, Aronson DC. Where do we stand with hepatoblastoma? A review. Cancer (2003) 98:66878. doi: $10.1002 / \mathrm{cncr} .11585$

8. Kahlert C, Melo SA, Protopopov A, Tang J, Seth S, Koch M, et al. Identification of double-stranded genomic DNA spanning all chromosomes with mutated KRAS and p53 DNA in the serum exosomes of patients with pancreatic cancer. J Biol Chem. (2014) 289:3869-75. doi: 10.1074/jbc.C113.532267

9. Melo SA, Luecke LB, Kahlert C, Fernandez AF, Gammon ST, Kaye J, et al. Glypican-1 identifies cancer exosomes and detects early pancreatic cancer. Nature (2015) 523:177-82. doi: 10.1038/nature14581

10. Yanez-Mo M, Siljander PR, Andreu Z, Zavec AB, Borras FE, Buzas EI, et al. Biological properties of extracellular vesicles and their physiological functions. J Extracell Vesicles (2015) 4:27066. doi: 10.3402/jev.v4. 27066

11. Raposo G, Stoorvogel W. Extracellular vesicles: exosomes, microvesicles, and friends. J Cell Biol. (2013) 200:373-83. doi: 10.1083/jcb.201211138

12. Colombo M, Raposo G, Thery C. Biogenesis, secretion, and intercellular interactions of exosomes and other extracellular vesicles. Annu Rev Cell Dev Biol. (2014) 30:255-89. doi: 10.1146/annurev-cellbio-101512-122326

13. Tkach M, Thery C. Communication by extracellular vesicles: where we are and where we need to go. Cell (2016) 164:1226-32. doi: 10.1016/j.cell.2016.01.043

14. Huotari J, Helenius A. Endosome maturation. Embo J. (2011) 30:3481-500. doi: 10.1038/emboj.2011.286

15. Akers JC, Gonda D, Kim R, Carter BS, Chen CC. Biogenesis of extracellular vesicles (EV): exosomes, microvesicles, retrovirus-like vesicles, and apoptotic bodies. J Neurooncol. (2013) 113:1-11. doi: 10.1007/s11060-013-1084-8

16. Gyorgy B, Szabo TG, Pasztoi M, Pal Z, Misjak P, Aradi B, et al. Membrane vesicles, current state-of-the-art: emerging role of extracellular vesicles. Cell Mol Life Sci. (2011) 68:2667-88. doi: 10.1007/s00018-011-0689-3

17. Ariazi J, Benowitz A, De Biasi V, Den Boer ML, Cherqui S, Cui H, et al. Tunneling nanotubes and gap junctions-their role in long-range intercellular communication during development, health, and disease conditions. Front Mol Neurosci. (2017) 10:333. doi: 10.3389/fnmol.2017.00333
[CIBERehd: JB, LB, and MP], Spain; Diputación Foral Gipuzkoa (JB: DFG15/010,DFG16/004), BIOEF (Basque Foundation for Innovation and Health Research: EiTB Maratoia BIO15/CA/016/BD to JB); Department of Health of the Basque Country (JB: 2013111173 and 2017111010; MP: 2015111100), and AECC Scientific Foundation (JB). AL and PO were funded by the Basque Government.
18. Ramachandran S, Palanisamy V. Horizontal transfer of RNAs: exosomes as mediators of intercellular communication. Wiley Interdiscip Rev RNA (2012) 3:286-93. doi: 10.1002/wrna.115

19. Liem M, Ang CS, Mathivanan S. Insulin mediated activation of PI3K/Akt signalling pathway modifies the proteomic cargo of extracellular vesicles. Proteomics (2017) 17:23-4. doi: 10.1002/pmic.201600371

20. Saha B, Momen-Heravi F, Kodys K, Szabo G. MicroRNA Cargo of extracellular vesicles from alcohol-exposed monocytes signals naive monocytes to differentiate into M2 macrophages. J Biol Chem. (2016) 291:149-59. doi: 10.1074/jbc.M115.694133

21. Keller S, Ridinger J, Rupp AK, Janssen JW, Altevogt P. Body fluid derived exosomes as a novel template for clinical diagnostics. J Transl Med. (2011) 9:86. doi: 10.1186/1479-5876-9-86

22. Ogorevc E, Kralj-Iglic V, Veranic P. The role of extracellular vesicles in phenotypic cancer transformation. Radiol Oncol. (2013) 47:197-205. doi: 10.2478/raon-2013-0037

23. Lindoso RS, Collino F, Vieyra A. Extracellular vesicles as regulators of tumor fate: crosstalk among cancer stem cells, tumor cells and mesenchymal stem cells. Stem Cell Investig. (2017) 4:75. doi: 10.21037/sci.2017.08.08

24. Katsuda T, Kosaka N, Ochiya T. The roles of extracellular vesicles in cancer biology: toward the development of novel cancer biomarkers. Proteomics (2014) 14:412-25. doi: 10.1002/pmic.201300389

25. Sadovska L, Santos CB, Kalnina Z, Line A. Biodistribution, uptake and effects caused by cancer-derived extracellular vesicles. J Circ Biomark (2015) 4:2. doi: $10.5772 / 60522$

26. Kogure T, Lin WL, Yan IK, Braconi C, Patel T. Intercellular nanovesiclemediated microRNA transfer: a mechanism of environmental modulation of hepatocellular cancer cell growth. Hepatology (2011) 54:1237-48. doi: $10.1002 /$ hep. 24504

27. Skog J, Wurdinger T, van Rijn S, Meijer DH, Gainche L, Sena-Esteves M, et al. Glioblastoma microvesicles transport RNA and proteins that promote tumour growth and provide diagnostic biomarkers. Nat Cell Biol. (2008) 10:1470-6. doi: 10.1038/ncb1800

28. Khan S, Aspe JR, Asumen MG, Almaguel F, Odumosu O, AcevedoMartinez S, et al. Extracellular, cell-permeable survivin inhibits apoptosis while promoting proliferative and metastatic potential. Br J Cancer (2009) 100:1073-86. doi: 10.1038/sj.bjc.6604978

29. Xiao D, Barry S, Kmetz D, Egger M, Pan J, Rai SN, et al. Melanoma cell-derived exosomes promote epithelial-mesenchymal transition in primary melanocytes through paracrine/autocrine signaling in the tumor microenvironment. Cancer Lett. (2016) 376:318-27. doi: 10.1016/j.canlet.2016.03.050

30. Harris DA, Patel SH, Gucek M, Hendrix A, Westbroek W, Taraska JW. Exosomes released from breast cancer carcinomas stimulate cell movement. PLoS ONE (2015) 10:e0117495. doi: 10.1371/journal.pone. 0117495

31. Haga H, Yan IK, Takahashi K, Wood J, Zubair A, Patel T. Tumour cell-derived extracellular vesicles interact with mesenchymal stem cells to modulate the microenvironment and enhance cholangiocarcinoma growth. J Extracell Vesicles (2015) 4:24900. doi: 10.3402/jev.v4.24900

32. Mu W, Rana S, Zoller M. Host matrix modulation by tumor exosomes promotes motility and invasiveness. Neoplasia (2013) 15:875-87. doi: $10.1593 /$ neo. 13786

33. Bouvy C, Gheldof D, Chatelain C, Mullier F, Dogne JM. Contributing role of extracellular vesicles on vascular endothelium haemostatic balance in cancer. J Extracell Vesicles (2014) 3. doi: 10.3402/jev.v3.24400 
34. Grange C, Tapparo M, Collino F, Vitillo L, Damasco C, Deregibus MC, et al. Microvesicles released from human renal cancer stem cells stimulate angiogenesis and formation of lung premetastatic niche. Cancer Res. (2011) 71:5346-56. doi: 10.1158/0008-5472.CAN-11-0241

35. Shao H, Chung J, Lee K, Balaj L, Min C, Carter BS, et al. Chip-based analysis of exosomal mRNA mediating drug resistance in glioblastoma. Nat Commun. (2015) 6:6999. doi: 10.1038/ncomms7999

36. Corcoran C, Rani S, O’Brien K, O’Neill A, Prencipe M, Sheikh R, et al. Docetaxel-resistance in prostate cancer: evaluating associated phenotypic changes and potential for resistance transfer via exosomes. PLoS ONE (2012) 7:e50999. doi: 10.1371/journal.pone.0050999

37. Chen WX, Liu XM, Lv MM, Chen L, Zhao JH, Zhong SL, et al. Exosomes from drug-resistant breast cancer cells transmit chemoresistance by a horizontal transfer of microRNAs. PLoS ONE (2014) 9:e95240. doi: 10.1371/journal.pone.0095240

38. Hoshino A, Costa-Silva B, Shen TL, Rodrigues G, Hashimoto A, Tesic Mark $\mathrm{M}$, et al. Tumour exosome integrins determine organotropic metastasis. Nature (2015) 527:329-35. doi: 10.1038/nature15756

39. Peinado H, Aleckovic M, Lavotshkin S, Matei I, Costa-Silva B, MorenoBueno G, et al. Melanoma exosomes educate bone marrow progenitor cells toward a pro-metastatic phenotype through MET. Nat Med. (2012) 18:883-91. doi: 10.1038/nm.2753

40. Chalmin F, Ladoire S, Mignot G, Vincent J, Bruchard M, Remy-Martin JP, et al. Membrane-associated Hsp72 from tumor-derived exosomes mediates STAT3-dependent immunosuppressive function of mouse and human myeloid-derived suppressor cells. J Clin Invest. (2010) 120:457-71. doi: 10.1172/JCI40483

41. Valenti R, Huber V, Filipazzi P, Pilla L, Sovena G, Villa A, et al. Human tumor-released microvesicles promote the differentiation of myeloid cells with transforming growth factor-beta-mediated suppressive activity on T lymphocytes. Cancer Res. (2006) 66:9290-8. doi: 10.1158/0008-5472.CAN-06-1819

42. Klibi J, Niki T, Riedel A, Pioche-Durieu C, Souquere S, Rubinstein E, et al. Blood diffusion and Th1-suppressive effects of galectin-9-containing exosomes released by Epstein-Barr virus-infected nasopharyngeal carcinoma cells. Blood (2009) 113:1957-66. doi: 10.1182/blood-2008-02-142596

43. van Niel G, D'Angelo G, Raposo G. Shedding light on the cell biology of extracellular vesicles. Nat Rev Mol Cell Biol. (2018) 19:213-28. doi: $10.1038 / \mathrm{nrm} .2017 .125$

44. Colombo M, Moita C, van Niel G, Kowal J, Vigneron J, Benaroch P, et al. Analysis of ESCRT functions in exosome biogenesis, composition and secretion highlights the heterogeneity of extracellular vesicles. J Cell Sci. (2013) 126(Pt 24):5553-65. doi: 10.1242/jcs.128868

45. Trajkovic K, Hsu C, Chiantia S, Rajendran L, Wenzel D, Wieland F, et al. Ceramide triggers budding of exosome vesicles into multivesicular endosomes. Science (2008) 319:1244-7. doi: 10.1126/science.1153124

46. Gulbins E, Kolesnick R. Raft ceramide in molecular medicine. Oncogene (2003) 22:7070-7. doi: 10.1038/sj.onc.1207146

47. de Gassart A, Geminard C, Fevrier B, Raposo G, Vidal M. Lipid raft-associated protein sorting in exosomes. Blood (2003) 102:4336-44. doi: 10.1182/blood-2003-03-0871

48. Laulagnier K, Grand D, Dujardin A, Hamdi S, Vincent-Schneider H, Lankar D, et al. PLD2 is enriched on exosomes and its activity is correlated to the release of exosomes. FEBS Lett. (2004) 572:11-4. doi: 10.1016/j.febslet.2004.06.082

49. Ghossoub R, Lembo F, Rubio A, Gaillard CB, Bouchet J, Vitale N, et al. Syntenin-ALIX exosome biogenesis and budding into multivesicular bodies are controlled by ARF6 and PLD2. Nat Commun. (2014) 5:3477. doi: $10.1038 /$ ncomms 4477

50. Perez-Hernandez D, Gutierrez-Vazquez C, Jorge I, Lopez-Martin S, Ursa A, Sanchez-Madrid F, et al. The intracellular interactome of tetraspaninenriched microdomains reveals their function as sorting machineries toward exosomes. J Biol Chem. (2013) 288:11649-61. doi: 10.1074/jbc.M112.445304

51. van Niel G, Charrin S, Simoes S, Romao M, Rochin L, Saftig P, et al. The tetraspanin CD63 regulates ESCRT-independent and -dependent endosomal sorting during melanogenesis. Dev Cell (2011) 21:708-21. doi: 10.1016/j.devcel.2011.08.019
52. Xiang X, Qiu R, Yao X, Arst HN Jr, Penalva MA, Zhang J. Cytoplasmic dynein and early endosome transport. Cell Mol Life Sci. (2015) 72:3267-80. doi: 10.1007/s00018-015-1926-y

53. Bonifacino JS, Glick BS. The mechanisms of vesicle budding and fusion. Cell (2004) 116:153-66. doi: 10.1016/S0092-8674(03)01079-1

54. Jahn R, Scheller RH. SNAREs-engines for membrane fusion. Nature Rev Mol Cell Biol. (2006) 7:631-43. doi: 10.1038/nrm2002

55. Piccin A, Murphy WG, Smith OP. Circulating microparticles: pathophysiology and clinical implications. Blood Rev. (2007) 21:157-71. doi: 10.1016/j.blre.2006.09.001

56. Mulcahy LA, Pink RC, Carter DR. Routes and mechanisms of extracellular vesicle uptake. J Extracell Vesicles. (2014) 3. doi: 10.3402/jev.v3.24641

57. Singh R, Pochampally R, Watabe K, Lu Z, Mo YY. Exosome-mediated transfer of miR-10b promotes cell invasion in breast cancer. Mol Cancer (2014) 13:256. doi: 10.1186/1476-4598-13-256

58. Richards KE, Zeleniak AE, Fishel ML, Wu J, Littlepage LE, Hill R. Cancer-associated fibroblast exosomes regulate survival and proliferation of pancreatic cancer cells. Oncogene (2017) 36:1770-8. doi: 10.1038 /onc. 2016.353

59. Kowal J, Tkach M, Thery C. Biogenesis and secretion of exosomes. Curr Opin Cell Biol. (2014) 29:116-25. doi: 10.1016/j.ceb.2014.05.004

60. Bobrie A, Krumeich S, Reyal F, Recchi C, Moita LF, Seabra MC, et al. Rab27a supports exosome-dependent and -independent mechanisms that modify the tumor microenvironment and can promote tumor progression. Cancer Res. (2012) 72:4920-30. doi: 10.1158/0008-5472.CAN-1 2-0925

61. Escola JM, Kleijmeer MJ, Stoorvogel W, Griffith JM, Yoshie O, Geuze HJ. Selective enrichment of tetraspan proteins on the internal vesicles of multivesicular endosomes and on exosomes secreted by human B-lymphocytes. J Biol Chem. (1998) 273:20121-7. doi: 10.1074/jbc.273.32.20121

62. Thery C, Regnault A, Garin J, Wolfers J, Zitvogel L, Ricciardi-Castagnoli P, et al. Molecular characterization of dendritic cell-derived exosomes. Selective accumulation of the heat shock protein hsc73. J Cell Biol. (1999) 147:599610. doi: $10.1083 /$ jcb.147.3.599

63. Morelli AE, Larregina AT, Shufesky WJ, Sullivan ML, Stolz DB, Papworth GD, et al. Endocytosis, intracellular sorting, and processing of exosomes by dendritic cells. Blood (2004) 104:3257-66. doi: 10.1182/blood-2004-03-0824

64. Hemler ME. Tetraspanin functions and associated microdomains. Nat Rev Mol Cell Biol. (2005) 6:801-11. doi: 10.1038/nrm1736

65. Barres C, Blanc L, Bette-Bobillo P, Andre S, Mamoun R, Gabius HJ, et al. Galectin-5 is bound onto the surface of rat reticulocyte exosomes and modulates vesicle uptake by macrophages. Blood (2010) 115:696-705. doi: 10.1182/blood-2009-07-231449

66. Naslund TI, Paquin-Proulx D, Paredes PT, Vallhov H, Sandberg JK, Gabrielsson S. Exosomes from breast milk inhibit HIV-1 infection of dendritic cells and subsequent viral transfer to CD4+ T cells. AIDS (2014) 28:171-80. doi: 10.1097/QAD.0000000000000159

67. Hao S, Bai O, Li F, Yuan J, Laferte S, Xiang J. Mature dendritic cells pulsed with exosomes stimulate efficient cytotoxic T-lymphocyte responses and antitumour immunity. Immunology (2007) 120:90-102. doi: 10.1111/j.1365-2567.2006.02483.x

68. Christianson HC, Svensson KJ, van Kuppevelt TH, Li JP, Belting M. Cancer cell exosomes depend on cell-surface heparan sulfate proteoglycans for their internalization and functional activity. Proc Natl Acad Sci USA. (2013) 110:17380-5. doi: 10.1073/pnas.1304266110

69. Atai NA, Balaj L, van Veen H, Breakefield XO, Jarzyna PA, Van Noorden CJ, et al. Heparin blocks transfer of extracellular vesicles between donor and recipient cells. J Neurooncol. (2013) 115:343-51. doi: 10.1007/s11060-013-1235-y

70. Escrevente C, Keller S, Altevogt P, Costa J. Interaction and uptake of exosomes by ovarian cancer cells. BMC Cancer (2011) 11:108. doi: 10.1186/1471-2407-11-108

71. Montecalvo A, Larregina AT, Shufesky WJ, Stolz DB, Sullivan ML, Karlsson JM, et al. Mechanism of transfer of functional microRNAs between mouse dendritic cells via exosomes. Blood (2012) 119:756-66. doi: 10.1182/blood-2011-02-338004 
72. Feng D, Zhao WL, Ye YY, Bai XC, Liu RQ, Chang LF, et al. Cellular internalization of exosomes occurs through phagocytosis. Traffic (2010) 11:675-87. doi: 10.1111/j.1600-0854.2010.01041.x

73. Herskovits JS, Burgess CC, Obar RA, Vallee RB. Effects of mutant rat dynamin on endocytosis. J Cell Biol. (1993) 122:565-78. doi: $10.1083 /$ jcb.122.3.565

74. Vallee RB, Herskovits JS, Aghajanian JG, Burgess CC, Shpetner HS. Dynamin, a GTPase involved in the initial stages of endocytosis. Ciba Found Symp. (1993) 176:185-93; discussion 93-7.

75. Ehrlich M, Boll W, Van Oijen A, Hariharan R, Chandran K, Nibert ML, et al. Endocytosis by random initiation and stabilization of clathrin-coated pits. Cell (2004) 118:591-605. doi: 10.1016/j.cell.2004.08.017

76. Fitzner D, Schnaars M, van Rossum D, Krishnamoorthy G, Dibaj P, Bakhti M, et al. Selective transfer of exosomes from oligodendrocytes to microglia by macropinocytosis. J Cell Sci. (2011) 124(Pt 3):447-58. doi: $10.1242 /$ jcs. 074088

77. Izquierdo-Useros N, Naranjo-Gomez M, Archer J, Hatch SC, Erkizia I, Blanco J, et al. Capture and transfer of HIV-1 particles by mature dendritic cells converges with the exosome-dissemination pathway. Blood (2009) 113:2732-41. doi: 10.1182/blood-2008-05-158642

78. Koumangoye RB, Sakwe AM, Goodwin JS, Patel T, Ochieng J. Detachment of breast tumor cells induces rapid secretion of exosomes which subsequently mediate cellular adhesion and spreading. PLoS ONE (2011) 6:e24234. doi: 10.1371/journal.pone.0024234

79. Svensson KJ, Christianson HC, Wittrup A, Bourseau-Guilmain E, Lindqvist E, Svensson LM, et al. Exosome uptake depends on ERK1/2heat shock protein 27 signaling and lipid Raft-mediated endocytosis negatively regulated by caveolin-1. J Biol Chem. (2013) 288:17713-24. doi: 10.1074/jbc.M112.445403

80. Al-Nedawi K, Meehan B, Kerbel RS, Allison AC, Rak J. Endothelial expression of autocrine VEGF upon the uptake of tumor-derived microvesicles containing oncogenic EGFR. Proc Natl Acad Sci USA. (2009) 106:3794-9. doi: 10.1073/pnas.0804543106

81. Corbet C, Feron O. Tumour acidosis: from the passenger to the driver's seat. Nat Rev Cancer. (2017) 17:577-93. doi: 10.1038/nrc.2017.77

82. Parolini I, Federici C, Raggi C, Lugini L, Palleschi S, De Milito A, et al. Microenvironmental $\mathrm{pH}$ is a key factor for exosome traffic in tumor cells. J Biol Chem. (2009) 284:34211-22. doi: 10.1074/jbc.M109.041152

83. Takahashi K, Yan IK, Kogure T, Haga H, Patel T. Extracellular vesiclemediated transfer of long non-coding RNA ROR modulates chemosensitivity in human hepatocellular cancer. FEBS Open Bio (2014) 4:458-67. doi: 10.1016/j.fob.2014.04.007

84. Qu Z, Wu J, Wu J, Luo D, Jiang C, Ding Y. Exosomes derived from HCC cells induce sorafenib resistance in hepatocellular carcinoma both in vivo and in vitro. J Exp Clin Cancer Res. (2016) 35:159. doi: 10.1186/s13046-016-0430-z

85. Conigliaro A, Costa V, Lo Dico A, Saieva L, Buccheri S, Dieli F, et al. CD90+ liver cancer cells modulate endothelial cell phenotype through the release of exosomes containing H19 lncRNA. Mol Cancer (2015) 14:155. doi: 10.1186/s12943-015-0426-x

86. He M, Qin H, Poon TC, Sze SC, Ding X, Co NN, et al. Hepatocellular carcinoma-derived exosomes promote motility of immortalized hepatocyte through transfer of oncogenic proteins and RNAs. Carcinogenesis (2015) 36:1008-18. doi: 10.1093/carcin/bgv081

87. Zhang Z, Li X, Sun W, Yue S, Yang J, Li J, et al. Loss of exosomal miR-320a from cancer-associated fibroblasts contributes to HCC proliferation and metastasis. Cancer Lett. (2017) 397:33-42. doi: 10.1016/j.canlet.2017.03.004

88. Ma J, Cai W, Zhang Y, Huang C, Zhang H, Liu J, et al. Innate immune cellderived microparticles facilitate hepatocarcinoma metastasis by transferring integrin alpha(M)beta(2) to tumor cells. J Immunol. (2013) 191:3453-61. doi: 10.4049/jimmunol.1300171

89. Masyuk AI, Huang BQ, Ward CJ, Gradilone SA, Banales JM, Masyuk $\mathrm{TV}$, et al. Biliary exosomes influence cholangiocyte regulatory mechanisms and proliferation through interaction with primary cilia. Am J Physiol Gastrointest Liver Physiol. (2010) 299:G990-9. doi: 10.1152/ajpgi.00093.2010

90. Arbelaiz A, Azkargorta M, Krawczyk M, Santos-Laso A, Lapitz A, Perugorria MJ, et al. Serum extracellular vesicles contain protein biomarkers for primary sclerosing cholangitis and cholangiocarcinoma. Hepatology (2017) 66:112543. doi: 10.1002/hep. 29291
91. Dutta S, Reamtong O, Panvongsa W, Kitdumrongthum S, Janpipatkul K, Sangvanich P, et al. Proteomics profiling of cholangiocarcinoma exosomes: A potential role of oncogenic protein transferring in cancer progression. Biochim Biophys Acta (2015) 1852:1989-99. doi: 10.1016/j.bbadis.2015.06.024

92. Claperon A, Mergey M, Nguyen Ho-Bouldoires TH, Vignjevic D, Wendum D, Chretien Y, et al. EGF/EGFR axis contributes to the progression of cholangiocarcinoma through the induction of an epithelial-mesenchymal transition. J Hepatol. (2014) 61:325-32. doi: 10.1016/j.jhep.2014.03.033

93. Yoshikawa D, Ojima H, Iwasaki M, Hiraoka N, Kosuge T, Kasai S, et al. Clinicopathological and prognostic significance of EGFR, VEGF, and HER2 expression in cholangiocarcinoma. Br J Cancer (2008) 98:418-25. doi: $10.1038 /$ sj.bjc. 6604129

94. Tamada S, Shibahara H, Higashi M, Goto M, Batra SK, Imai K, et al. MUC4 is a novel prognostic factor of extrahepatic bile duct carcinoma. Clin Cancer Res. (2006) 12(14 Pt 1):4257-64. doi: 10.1158/1078-0432.CCR-05-2814

95. Sasaki M, Matsubara T, Yoneda N, Nomoto K, Tsuneyama K, Sato Y, et al. Overexpression of enhancer of zeste homolog 2 and MUC1 may be related to malignant behaviour in intraductal papillary neoplasm of the bile duct. Histopathology (2013) 62:446-57. doi: 10.1111/his.12016

96. Sulpice L, Rayar M, Turlin B, Boucher E, Bellaud P, Desille M, et al. Epithelial cell adhesion molecule is a prognosis marker for intrahepatic cholangiocarcinoma. J Surg Res. (2014) 192:117-23. doi: 10.1016/j.jss.2014.05.017

97. Chaiyadet S, Sotillo J, Smout M, Cantacessi C, Jones MK, Johnson MS, et al. Carcinogenic liver fluke secretes extracellular vesicles that promote cholangiocytes to adopt a tumorigenic phenotype. J Infect Dis. (2015) 212:1636-45. doi: 10.1093/infdis/jiv291

98. Liu W, Chen S, Liu B. Diagnostic and prognostic values of serum exosomal microRNA-21 in children with hepatoblastoma: a Chinese population-based study. Pediatr Surg Int. (2016) 32:1059-65. doi: 10.1007/s00383-016-3960-8

99. Jiao C, Jiao X, Zhu A, Ge J, Xu X. Exosomal miR-34s panel as potential novel diagnostic and prognostic biomarker in patients with hepatoblastoma. J Pediatr Surg. (2017) 52:618-24. doi: 10.1016/j.jpedsurg.2016.09.070

100. Wang W, Li H, Zhou Y, Jie S. Peripheral blood microvesicles are potential biomarkers for hepatocellular carcinoma. Cancer Biomark (2013) 13:351-7. doi: 10.3233/CBM-130370

101. Julich-Haertel H, Urban SK, Krawczyk M, Willms A, Jankowski K, Patkowski W, et al. Cancer-associated circulating large extracellular vesicles in cholangiocarcinoma and hepatocellular carcinoma. J Hepatol. (2017) 67:282-92. doi: 10.1016/j.jhep.2017.02.024

102. Li L, Masica D, Ishida M, Tomuleasa C, Umegaki S, Kalloo AN, et al. Human bile contains microRNA-laden extracellular vesicles that can be used for cholangiocarcinoma diagnosis. Hepatology (2014) 60:896-907. doi: 10.1002/hep.27050

103. Ge X, Wang Y, Nie J, Li Q, Tang L, Deng X, et al. The diagnostic/prognostic potential and molecular functions of long non-coding RNAs in the exosomes derived from the bile of human cholangiocarcinoma. Oncotarget (2017) 8:69995-70005. doi: 10.18632/oncotarget.19547

104. Severino V, Dumonceau JM, Delhaye M, Moll S, Annessi-Ramseyer I, Robin $\mathrm{X}$, et al. Extracellular vesicles in bile as markers of malignant biliary stenoses. Gastroenterology (2017) 153:495-504 e8. doi: 10.1053/j.gastro.2017.04.043

105. Sohn W, Kim J, Kang SH, Yang SR, Cho JY, Cho HC, et al. Serum exosomal microRNAs as novel biomarkers for hepatocellular carcinoma. Exp Mol Med. (2015) 47:e184. doi: 10.1038/emm.2015.68

106. Wang H, Hou L, Li A, Duan Y, Gao H, Song X. Expression of serum exosomal microRNA-21 in human hepatocellular carcinoma. Biomed Res Int. (2014) 2014:864894. doi: 10.1155/2014/864894

107. Qu Z, Wu J, Wu J, Ji A, Qiang G, Jiang Y, et al. Exosomal miR-665 as a novel minimally invasive biomarker for hepatocellular carcinoma diagnosis and prognosis. Oncotarget (2017) 8:80666-78. doi: 10.18632/oncotarget.20881

108. Sugimachi K, Matsumura T, Hirata H, Uchi R, Ueda M, Ueo H, et al. Identification of a bona fide microRNA biomarker in serum exosomes that predicts hepatocellular carcinoma recurrence after liver transplantation. $\mathrm{Br} \mathrm{J}$ Cancer (2015) 112:532-8. doi: 10.1038/bjc.2014.621

109. Liu W, Hu J, Zhou K, Chen F, Wang Z, Liao B, et al. Serum exosomal miR$125 \mathrm{~b}$ is a novel prognostic marker for hepatocellular carcinoma. OncoTargets Ther. (2017) 10:3843-51. doi: 10.2147/OTT.S140062 
110. Gyorgy B, Hung ME, Breakefield XO, Leonard JN. Therapeutic applications of extracellular vesicles: clinical promise and open questions. Annu Rev Pharmacol Toxicol. (2015) 55:439-64. doi: 10.1146/annurev-pharmtox-010814-124630

111. Robbins PD, Morelli AE. Regulation of immune responses by extracellular vesicles. Nat Rev Immunol. (2014) 14:195-208. doi: 10.1038/nri3622

112. Kim SM, Kim HS. Engineering of extracellular vesicles as drug delivery vehicles. Stem Cell Investig. (2017) 4:74. doi: 10.21037/sci.2017.08.07

113. Santangelo L, Battistelli C, Montaldo C, Citarella F, Strippoli R, Cicchini C. Functional roles and therapeutic applications of exosomes in hepatocellular carcinoma. Biomed Res Int. (2017) 2017:2931813. doi: 10.1155/2017/2931813

114. Wang F, Hongwei T, Li L, Piontek K, Sakaguchi M, Selaru FM. Exosome - miR-335 as a novel therapeutic strategy in hepatocellular carcinoma. Hepatology (2017) 67:940-54. doi: 10.1002/hep.29586

115. Lou G, Song X, Yang F, Wu S, Wang J, Chen Z, et al. Exosomes derived from miR-122-modified adipose tissue-derived MSCs increase chemosensitivity of hepatocellular carcinoma. J Hematol Oncol. (2015) 8:122. doi: 10.1186/s13045-015-0220-7

116. Li L, Piontek K, Ishida M, Fausther M, Dranoff JA, Fu R, et al. Extracellular vesicles carry microRNA-195 to intrahepatic cholangiocarcinoma and improve survival in a rat model. Hepatology (2017) 65:501-14. doi: 10.1002/hep.28735

117. Lv LH, Wan YL, Lin Y, Zhang W, Yang M, Li GL, et al. Anticancer drugs cause release of exosomes with heat shock proteins from human hepatocellular carcinoma cells that elicit effective natural killer cell antitumor responses in vitro. J Biol Chem. (2012) 287:15874-85. doi: 10.1074/jbc.M112.340588

118. Xiao W, Dong W, Zhang C, Saren G, Geng P, Zhao H, et al. Effects of the epigenetic drug MS-275 on the release and function of exosome-related immune molecules in hepatocellular carcinoma cells. Eur J Med Res. (2013) 18:61. doi: 10.1186/2047-783X-18-61

119. Ko SF, Yip HK, Zhen YY, Lee CC, Lee CC, Huang CC, et al. Adiposederived mesenchymal stem cell exosomes suppress hepatocellular carcinoma growth in a rat model: apparent diffusion coefficient, natural killer T-Cell responses, and histopathological features. Stem Cells Int. (2015) 2015:853506. doi: $10.1155 / 2015 / 853506$
120. Rao Q, Zuo B, Lu Z, Gao X, You A, Wu C, et al. Tumor-derived exosomes elicit tumor suppression in murine hepatocellular carcinoma models and humans in vitro. Hepatology (2016) 64:456-72. doi: 10.1002/hep.28549

121. Lu Z, Zuo B, Jing R, Gao X, Rao Q, Liu Z, et al. Dendritic cell-derived exosomes elicit tumor regression in autochthonous hepatocellular carcinoma mouse models. J Hepatol. (2017) 67:739-48. doi: 10.1016/j.jhep.2017.05.019

122. Lotvall J, Hill AF, Hochberg F, Buzas EI, Di Vizio D, Gardiner C, et al. Minimal experimental requirements for definition of extracellular vesicles and their functions: a position statement from the International Society for Extracellular Vesicles. J Extracell Ves. (2014) 3:26913. doi: 10.3402/jev.v3.26913

123. Witwer KW, Buzas EI, Bemis LT, Bora A, Lasser C, Lotvall J, et al. Standardization of sample collection, isolation and analysis methods in extracellular vesicle research. J Extracell Ves. (2013) 2:20360. doi: 10.3402/jev.v2i0.20360

124. Vozel D, Ursic B, Krek JL, Stukelj R, Kralj-Iglic V. Applicability of extracellular vesicles in clinical studies. Eur J Clin Invest. (2017) 47:305-13. doi: 10.1111/eci.12733.

125. Stahl PD, Raposo G. Exosomes and extracellular vesicles: the path forward. Essays Biochem. (2018) 62:119-24. doi: 10.1042/EBC20170088

126. Bastos N, Ruivo CF, da Silva S, Melo SA. Exosomes in cancer: Use them or target them? Sem Cell Dev Biol. (2018) 78:13-21. doi: 10.1016/j.semcdb.2017.08.009

Conflict of Interest Statement: The authors declare that the research was conducted in the absence of any commercial or financial relationships that could be construed as a potential conflict of interest.

Copyright (c) 2018 Lapitz, Arbelaiz, Olaizola, Aranburu, Bujanda, Perugorria and Banales. This is an open-access article distributed under the terms of the Creative Commons Attribution License (CC BY). The use, distribution or reproduction in other forums is permitted, provided the original author(s) and the copyright owner(s) are credited and that the original publication in this journal is cited, in accordance with accepted academic practice. No use, distribution or reproduction is permitted which does not comply with these terms. 